\title{
Post-merger Integration Approaches: Case Analysis of the One. Vip Macedonia Merger
}

\author{
Dushica Stevchevska-Srbinoska, $\mathrm{PhD}$ \\ University American College Skopje \\ Boulevard III Makedonska Brigada 60, Skopje, Macedonia \\ Tel: 389-2-246-3156_E-mail: dusica@uacs.edu.mk
}

Edi Smokvarski, MBA

University American College Skopje

Boulevard III Makedonska Brigada 60, Skopje, Macedonia

Tel: 389-2-246-3156Ｅ-mail: smokvarski@uacs.edu.mk

Received: Nov. 7, 2016 Accepted: Dec. 20, $2016 \quad$ Published: December 20, 2016

doi:10.5296/ajfa.v8i2.10288 URL: http://dx.doi.org/10.5296/ajfa.v8i2.10288

\begin{abstract}
Selecting the best integration approach is a meticulous and sensitive process that can mold the completion of the merger and/or acquisition transaction. In this paper, I discuss that implementing the proper integration approach leads to mitigating or increasing impending risks when going into major company restructuring events. If proper selection and execution takes place, and all related processes and expectations of the parties involved are duly taken into account, successful post-merger integration can be concluded in the Republic of Macedonia in spite of numerous difficulties. One of the greatest risk factors certainly lies in the satisfaction or dissatisfaction of the work force which is of vital meaning for the operational excellence of every entity. Three different integration approaches - absorption, symbiosis, and preservation - are observed through literature overview and particular transactions. Additionally, I study the example of the integration approach adopted by one. Vip doo Skopje following the merger of Vip operator dooel Skopje and ONE in 2015, accentuating that multiple factors can increase or deteriorate the chances of integration success.
\end{abstract}

Keywords: Integration process, Integration approach, Merger and acquisition, Macedonian market 


\section{MInstitute"}

\section{Introduction}

Organizational design is the process that enables managers to select and manage the individual dimensions and components of the organizational culture for the purpose of attaining the organization goals. Organizational structure is the formal system of tasks and relationships that leads to control, coordination, and motivation of employees while enabling their cooperation. The manager's task is to create an organizational structure and culture that:

1. Encourage employees to work in a dedicated manner and to provide support for each other

2. Enable people and groups to cooperate effectively (Popovski, 2001).

Structure and culture have a vast impact on the:

1. Team work and cooperation,

2. Inter-group and inter-departmental relations.

3. Behavior,

4. Motivation,

5. Results,

Structure and culture design and evolution influence the behavior of individuals and groups within every organization. Once the desired behavior, attitude and goals of the organization members are settled, one can design the structure and proceed with developing cultural values and norms that will set the grounds to acquire the desired attitudes, comportment and goals. Organizations base these decisions on the design of potential conditions they needs to face, which have to be considered upon planning. The three basicconditions that have influence on the design of structure and culture of the organization are:

- Organization surroundings

- Technology adopted and used by the organization, and

- Strategic direction of the company (Walter, 2004).

The above-stated represents basis for further differentiation of the organizations.

Differentiation is the process of creating groups of individuals and responsibilities for the purpose of producing goods and services. On the other hand, function represents group of people who work together and execute the same or similar type of tasks and occupy similar positions within the organization. As companies develop, work effort gets further classified into more individual functions, which requires further differentiation into more departments/units. Department is a group of functions created for the purpose of enabling the enterprise to produce and offer its goods and services to customers. When developing the organizational structure, management needs to differentiate and group the organizational activities according to function and division for the purpose of attaining the enterprise goals.

In general, most authors categorize all enterprises according to the following three 
organizational structures which vary based on the relations that bridge the organizational functions and units:

1. Functional structure

2. Unit structure: according to product/service, market and geographic location, and

3. Matrix (Divisional) organizational structure.

Table 1. Types of organizational structure

\begin{tabular}{|c|c|c|}
\hline & Advantages & Weaknesses \\
\hline $\begin{array}{l}\text { Functional } \\
\text { structure }\end{array}$ & $\begin{array}{l}\text { - Simple communication between } \\
\text { specialists } \\
\text { - Timely decision making } \\
\text { - Learning organization } \\
\text { - Team work } \\
\text { - Eases the evaluation of } \\
\text { employees across all levels }\end{array}$ & $\begin{array}{l}\text { - Difficulties upon servicing the } \\
\text { needs for all products that are } \\
\text { offered on the market } \\
\text { - Complicated coordination } \\
\text { - Complicated support for all } \\
\text { (geographic) regions } \\
\text { - Not suitable for older, } \\
\text { complex organizations }\end{array}$ \\
\hline Unit structure & $\begin{array}{l}\text { - Ease of communication } \\
\text { - Improved focus on various } \\
\text { services, products, or consumers } \\
\text { - Adapted management and } \\
\text { solution of problems } \\
\text { - Ease of team work } \\
\text { - Clear connection between } \\
\text { results and rewards } \\
\text { - Modelled services }\end{array}$ & $\begin{array}{l}\text { - High operational and } \\
\text { management costs } \\
\text { - Poor inter-departmental } \\
\text { communication/frequent } \\
\text { conflicts }\end{array}$ \\
\hline $\begin{array}{l}\text { Matrix } \\
\text { structure }\end{array}$ & $\begin{array}{l}\text { - Support for fast product } \\
\text { development } \\
\text { - Great communication and } \\
\text { cooperation between team } \\
\text { members } \\
\text { - Innovation and creativity }\end{array}$ & $\begin{array}{l}\text { - Role ambiguity } \\
\text { - Stressful work conditions } \\
\text { - Limited promotion } \\
\text { opportunities }\end{array}$ \\
\hline
\end{tabular}

Source: Lajoux, 2006

The functional structure comprehends activity structuring according to functions such as production, procurement, marketing, finance, sales, etc. The segment structure goes for activity grouping based on market presence, i.e. markets that the enterprise serves or geographic location covered. The matrix structure is complex and based on activity structuring according to functions and projects, where communication is both horizontal and vertical.

\section{- Integration: Mechanisms for improved coordination}




\section{Macrothink}

Asian Journal of Finance \& Accounting

ISSN 1946-052X

2016, Vol. 8, No. 2

The more grand and the more complex an entity is, the larger its hierarchy. Complex organizations are comprised of multiple layers of hierarchy, while lean organizations have merely few.

Integration issues amongst hierarchy levels arise when a given entity becomes more complex. These issues are followed by communication difficulties and problems in decision-making processes (KPMG, 2011). Also, it takes more time to deliver messages up and down the hierarchy tree, which slows down the decision-making processes. Information messages lose core tone or are filtered in a way that managers interpret these messages according to their personal interest (Davis, 2000). These problems deteriorate the quality of decision making even further.

In order to reduce communication and decision-making difficulties which follow the growth process of every entity, especially in mergers and acquisitions, it is indispensable to take several steps such as:

- Decentralization

- Mutual adaptation

- Teams

- Personal contact.

All these actions enable analysis of communication problems across multiple points without transferring minor details and messages to top management. At the same time, delegating major work duties to lower echelons can increase motivation and challenge employees, which is very essential in major restructuring projects such as mergers and acquisitions.

\section{Integration approaches}

Three integration approaches are identified and analyzed by numerous researchers. Their implementation is dependent on the strategic intentions behind every merger and/or acquisition event (Pearson M, 1998).

Strategic interdependence:

Organizational

\begin{tabular}{|c|c|}
\hline \multicolumn{1}{c}{ Low } & High \\
\hline Preservation & Symbiosis \\
\hline Holding & Absorption \\
\hline
\end{tabular}

Figure 1. Integration approaches

Source: Haspeslagh, P., and Jemison D., 1991

The absorption approach is normally preferred in mergers and acquisitions within the same industrial segment and is based on the need for economy of scope and operating efficiency due to similarity of operations. It is applied in order to reinforce or expand market presence, 
such as presented in the Case study in the following chapter of this paper. Absorption calls for timely resolution of cultural difficulties.

Symbiosis is primarily applied in transactions between industrial segments where cultural differences can be quite striking. Eventually, high integration is needed within certain functional areas for the purpose of gaining merger and acquisition benefits, such as cross-sales and sales network merger. Symbiosis is applied in transactions where larger market presence is indispensable but the cultural differences are too grand to remove them within a short period. This is why the slow symbiotic approach is more adequate.

The preservation approach focuses on transactions in a new industry/segment for the aim of transferring specific skills or knowledge to the acquiring entity or to the other transaction participant(s). In most cases, the cultural differences between the two entities are big driven by operations in different industrial segments. Therefore, the merging entities are encouraged to continue operating individually with a high degree of autonomy. Also, the preservation approach may be applied when the acquirer is interested in entering a new sub-segment within the same industrial branch or in entering a new geographic region (country). Hence, the acquired entity remains, more or less, untouched in the aftermath of the transaction.

Finally, the holding structure comprehends sharing of particular risks, financial transfers and management. Integration is not in the scope of these organizations as functions and departments do not merge in practice. Hence, holding approach will not be evaluated in this paper in further details.

The desired integration level of individual operating segments following a given merger/acquisition transaction may differ to the overall integration. That said preservation may aim at high integration across several domains such as IT systems, data processing, accounting and internal audit. The remaining areas may be unaffected or may be slightly adjusted to the operations of the acquiring entity. Since absorption and symbiosis ask for high integration, albeit at a different pace, most of the operations should be encompassed in a similar manner.

Nevertheless, exceptions to the rule exist, especially when it comes to symbiotic acquisitions where some domains are excluded from the integration efforts. Such is the example of the acquisition of Transped Komerc doo Skopje (Macedonia) by Viator \&Vektor Logistika from Slovenia where management decided to integrate all functions but the retail brands and specific products. On the other hand, having in mind the high autonomy granted by the preservation approach, one could expect that integration will not be applied across most operations. Nonetheless, the acquirer may embark on rather insistent integration of several functional domains for the purpose of establishing a greater financial and operational control. This was the case of the 2006 acquisition of On.Net Macedonia conducted by ONE Macedonia (former Cosmofon), where high integration was pursued for IT, accounting, and audit systems. Branding was rapidly integrated as well. Only a select set of operations, such as differentiated customer offer in part of the fixed communications segment, preserved their uniformity. 
Management often handles several diverse integration timelines and priorities that touch upon multiple operation domains:

- Reporting responsibilities

- Accounting/auditfunction

- IT systems

- Human resource procedures and compensation/benefit plans

- Customer contacts

- Product lines and product logistics services

- Branding and marketing.

Speed and communication remain core aspects in every merger and acquisition integration. The decision-making process needs to be timely in order to minimize uncertainties and integration fatigue faced by employees and customers (Atkinson et al., 2015).

\section{Case study - Integration approach in one.Vip merger}

Company and transaction summary:

This paper will illustrate the importance of the acumen reached upon integrating through the example of one.Vip doo following the merger event of Vip operator dooel Skopje, Macedonian subsidiary of the Telekom Austria Group established in 2007, and ONE in Q4 2015, Telekom Slovenije's subsidiary established in 2003 as Cosmofon.(Telekom Austria Group Newsroom, 2015).Prior to merging, ONE occupied the third position in the Macedonian mobile communications market, with SIM market share of more than $26 \%$ at the end of Q3 2015 (approximately 600k subscribers). In 2014, ONE achieved total revenues and EBITDA of approximately $75.7 \mathrm{mn}$ EUR and $10.6 \mathrm{mn}$ EUR respectively. Vip operator on the other hand, had mobile market share of $27 \%$ prior to the transaction, with 2014 revenues somewhat below 60mnEUR, and EBITDA similar to ONE. The main driver behind the merger was to create a new enterprise with improved competitiveness and investment strength. In the essence, one.Vip was expected to generate benefits and quality to various customer segments, while encouraging competition on product, price and quality of services.

Following the transaction approval by the Macedonian Commission for Protection of Competition, $55 \%$ of the new entity's ownership remained in the hands of Telekom Austria Group, with Telekom Austria retaining sole control over one.Vip. Call and put options for the exit of Telekom Slovenije Group were foreseen within three years following the transaction. Core condition to the merger approval was to enable MVNO access to a third entrantin order to ensure competitiveness of products and prices on the Macedonian telecommunications market.

Integration activities:

\section{Leadership structure:}


- It was initially decided to retain Nikola Ljushev (CEO of Vip operator dooel Skopje) in the position of CEO of the new entity one.Vip doo Skopje. The CMO and CFO at the time were dismissed from their positions and reassigned to the holding headquarters.

- Nonetheless, Ljushev was degraded shortly after to the position of managing director as top management functions for one.Vip were extended to another operator from the Telekom Austria Group - Vipnet Croatia.This top management restructuring took by surprise the employees of one.Vip as Ljushev had occupied the CEO position almost from the beginning of operations of Vip operator dooel Skopje in 2007 when the entity was incorporated in the Macedonian market as a greenfield investment.

\section{Communication:}

- Failure in communicating the devotion to the reinforcement of their market presence in the Republic of Macedonia: most of the one.Vip employees were not persuaded in the coherence of the one.Vip market strategy. In fact, there was a common misunderstanding that one.Vip is primarily focused on delivering communications products based solely on the technology that Vip operator dooel Skopje had to offer before the merger, while ignoring the in-house developed services and systems of ONE. This misunderstanding was further reflected to their consumers. Furthermore, the situation led to losing most of the key talents of both merging entities, essentially starting with ONE, which burdened the hiring and retaining process.

\section{Human resources:}

- Human resource substitution: cca. 200 employees were fired or left the new company following one year of the merger transaction. The core explanation offered was overlap of duties, job functions, and similarity of operations of the merging entities. The genuine corporate motive was cost savings and effectuation of merger synergies.

- Selection process: the publicly acclaimed version was that retained employees were selected on the basis of merit and talent. However, selection was rather individual and based ratheron the opinion of middle management/supervisors and involved personal bias.

- Poor communication: although the entity aimed for a transparent selection process, the communication efforts via e-mail, intranet publications and meetings with senior management were insufficient. Part of the staff claimed that they were fired due to not having signed a contract for permanent employment prior to the merger, which made it easy to dismiss them when contract period expired.

- Preference for retaining the management of Vip operator dooel Skopje: prior to merging, ONE middle management were offered attractive compensation packages to motivate them to leave the company. Those who stayed were offered lower level positions and were degraded several scales down the organizational ladder, with the exception of few that managed to retain their department management position in the new entity. 
- Attempt to prevent employee loss: aware of employee disappointment, one.Vip tried to explain that the merger transaction was successfully completed and that in due course business will continue to run as usual. Yet, employees were unhappy with the new work environment whereby they were required to work long hours and were not offered any financial compensation for the additional work effort and stress on the work place. Communication failed, and one.Vip continued to lose key talent to competition and to other industries.

- Neutralizing cultural differences: the two main cultural conflicts that impeded onstaff motivation were the more rigid decision-making processes based on financial weight of projects and market decisions in Vip operator dooel as opposed to propulsive pricing processes and customer sales subordination culture in ONE, i.e. Austrian vs. Greek style organizational culture ${ }^{1}$.

\section{Implemented integration level}

High degree of integration

\section{Technology and Information Systems}

- It was decided to retain Vip operator's customer support, billing and collection, and finance systems. Regarding the telecommunication network, the assets were merged in a way that the best items were tested and selected (i.e. base stations with highest area and population coverage). Frequency range also was merged based on best/most used frequencies selection, with Regulator (i.e. Macedonian Agency for electronic communications) permit to sell redundant frequency lots to the sole mobile communications competitor, T-Mobile Macedonia.

\footnotetext{
${ }^{1}$ Cosmote Greece was the founder of ONE, former Cosmofon Macedonia. Understandably, the initial owner had left their cultural landmark on the organizational structure and processes of the entity. 
Table 2. Ranking of the one.Vip post-merger integration effectiveness

\begin{tabular}{|c|c|c|}
\hline Domain & Ranking & Outcome \\
\hline Employee retention & - & $\begin{array}{l}\text { One year into the merger (fall 2016), } \\
\text { one.Vip continued losing key talents }\end{array}$ \\
\hline Technical system & $?$ & On-going integration as of research date \\
\hline Sharing of knowledge & - & $\begin{array}{l}\text { Loss of key talents, lack of knowledge } \\
\text { codification for in-house developed } \\
\text { systems and products }\end{array}$ \\
\hline Customer retention & - & $\begin{array}{l}\text { As of fall 2016, one.Vip continued } \\
\text { experiencing drop in subscriber base } \\
\text { and customer dissatisfaction }\end{array}$ \\
\hline $\begin{array}{l}\text { Sales network (direct, indirect, } \\
\text { key account) }\end{array}$ & $?$ & $\begin{array}{l}\text { Many indirect master dealer contracts } \\
\text { were discontinued due to preferred } \\
\text { provider selection; shops were closed to } \\
\text { reduce sales costs, sales people were } \\
\text { laid off, which increased dissatisfaction } \\
\text { and uncertainty about future. } \\
\text { Nonetheless, the sales network } \\
\text { capilarilty was higher than before the } \\
\text { merger. }\end{array}$ \\
\hline Cross-selling & $?$ & $\begin{array}{l}\text { Customer dissatisfaction increased as } \\
\text { technical problems due to system } \\
\text { mergers came to surface, which made } \\
\text { upselling and cross-selling difficult }\end{array}$ \\
\hline Economy of scope & ?/- & $\begin{array}{l}\text { Difficulty in stabilizing prices on the } \\
\text { communications market and negative } \\
\text { customer reaction to higher prices } \\
\text { following the merger. Difficulties in } \\
\text { realizing expected merger synergies in } \\
\text { the form of higher income per } \\
\text { subscriber and lower subsidies in order } \\
\text { to prevent negative customer reaction. }\end{array}$ \\
\hline
\end{tabular}

Given the absence of a clear leadership structure, stable communication channels, and determination to reinforce employee motivation, the one-year post-merger period proved to have damaging impact on the human relations which pointed to an inefficient integration process. As the merged entity is stepping into the second post-transaction year, integration is still on-going and final outcomes are yet to be seen and analyzed.

\section{Conclusion}

A wide spectrum of participants is directly and indirectly involved in every merger and acquisition transaction. These parties impact and are impacted by major restructuring events 


\section{Macrothink}

such as mergers and acquisition, and the influence is reciprocal.

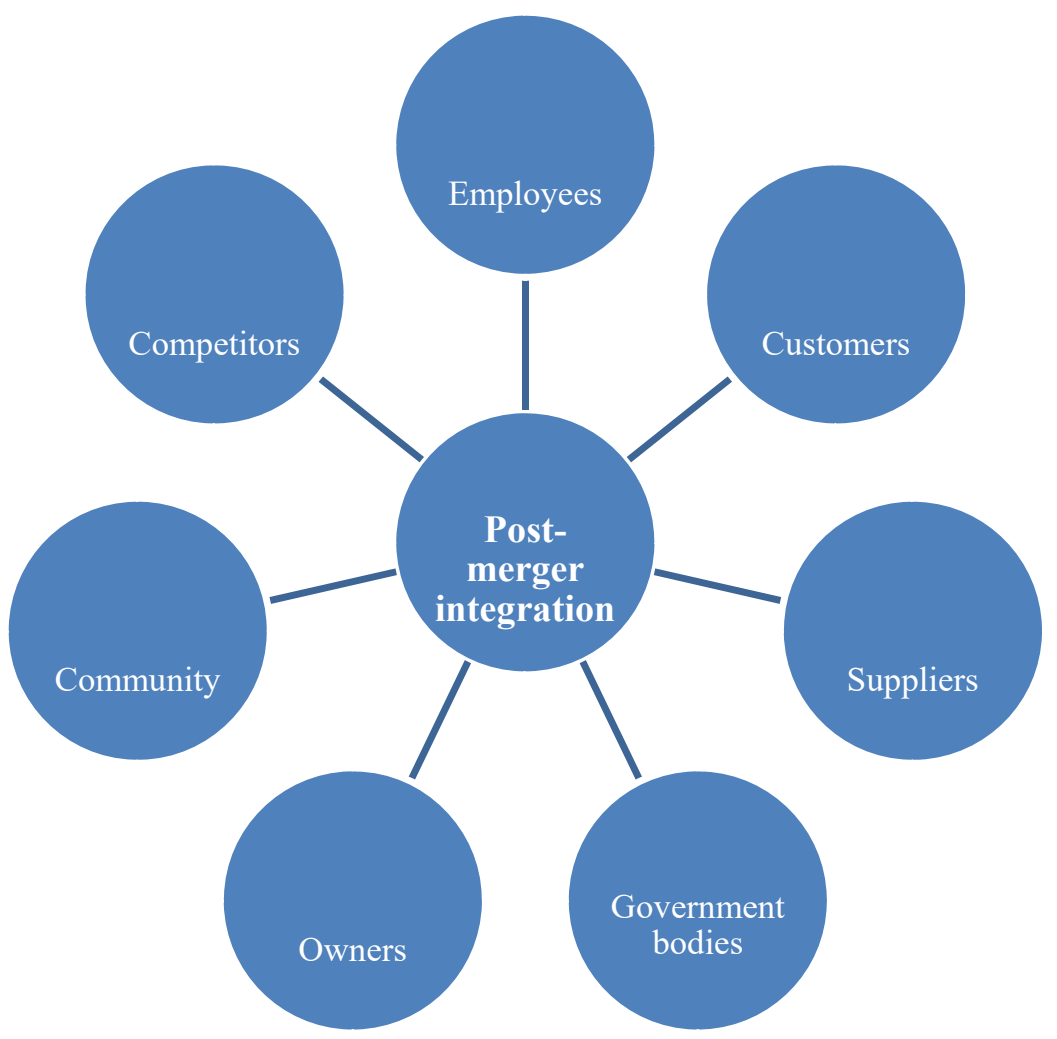

Figure 2. Participants in the merger and acquisition integration process

Employees, customers, vendors, government bodies and agencies, private investors, the communities/geographic regions where these entities operate and cooperate with, along with market competitors are important factors to the merger success, as well as for the longevity and success of the new entity. Ergo, managers must unequivocably dedicate their full attention to:

- Preserving and growing the current customer portfolio

- Georgraphic presence, especially when it comes to serving larger markets

- Economy of scale in revenue generating activities, full utilization of the available sales channels and their expansion, in particular through cross-selling

- Economy od scope in cost managememt along with operating efficiency

- Evaluation of the equity and liability structure

- Supply of products/services and brands

- Human resources, knowledge codification, and knowledge transfer

- Technology and infrastructure 


\section{Macrothink}

Asian Journal of Finance \& Accounting

ISSN 1946-052X

2016, Vol. 8, No. 2

Given the theoretical research and case study conducted using the available data from the one.Vip merger integration, it is evident that the integration process must be aligned with the pre-set acquisition goals. Implemeting the wrong approach or the right approach in the wrong manner may provoke negativeconsequences since all entities and enterpreneurial operations depend on the quality and adequacy of the human factor which is highly mobile.

\section{Acknowledgement}

The research is supported by UACS Skopje.

\section{References}

Atkinson, S., \& Gary, M.S. (2015). Creating Value in the Merger and Acquisition Integration Process, Proceedings of the 33rd International Conference of the System Dynamics Society Cambridge, Massachusetts, USA -- July 19-23, 2015, System Dynamics Society, Cambridge, Massachusetts, USA, presented at International Conference of the System Dynamics Society, Cambridge, Massachusetts, USA.

Davis, Steven. (2000). Bank Mergers: Lessons for the Future, London: Macmillan Press. https://doi.org/10.1057/9780230509399

Haspeslagh, P., \& Jemison, D. (1991). Managing Acquisitions. New York: Free Press.

KPMG. (2011). "Post Merger People Integration", full text available on: https://www.kpmg.com/IN/en/IssuesAndInsights/ArticlesPublications/Documents/Post\%20M erger\%20People\%20Integration.pdf.

Lajoux, A. Reed. (2006). The Art of M\&A Integration. A Guide to Merging Resources, Processes and Reponsibilities, The McGraw-Hill Companies, Inc.

Popovski, Vasil. (2001). The influence of the organizational structure on company operations, Ekonomski Institut Skopje.

Telekom Austria Group Newsroom. (2015). "Macedonian Competition Authority approves Merger of Vip Operator with ONE." full text available on: http://www.telekomaustria.com/en/newsroom/2015-7-8-macedonian-competition-authority-a pproves-merger-of-vip-operator-with-one.1.

Walter, Ingo. (2004). Mergers and Acquisitions in Banking and Finance. What Works, What Fails, and Why, New York: Oxford University Press Inc.

\section{Copyright Disclaimer}

Copyright for this article is retained by the author(s), with first publication rights granted to the journal.

This is an open-access article distributed under the terms and conditions of the Creative Commons Attribution license (http://creativecommons.org/licenses/by/3.0/). 